\title{
On Simultaneous Measurements with Rotor, Wing and Acoustic Gurrent Meters, Moored in Shallow Water
}

\author{
Hermann Kuhn, Detlef Quadfasel, Friedrich Schott and Walter Zenk \\ UDC 551.46.085:551.465.53; Western Baltic, Marsden square 21540
}

\section{Summary}

In two closely spaced moorings in the Kiel Bight, four different current meters two rotor current meters (Aanderaa and Vector averaging), an acoustic current meter (designed by Gytre), and a pendulum current meter (designed by Niskin) were moored for 22 days. The Vector averaging current meter (VACM) was used as reference instrument on one mooring with the floatation at $7 \mathrm{~m}$ depth. The floatation of the second mooring was at $5 \mathrm{~m}$ depth in the first 17 days of the experiment, but in $2.7 \mathrm{~m}$ depth in the last 5 days to make their mooring more effected by surface waves. The Niskin wing current meter was most effected by wave-induced mooring motion. The Gytre instrument showed the smallest surface-wave effects. The vector variances of this instrument in $7.4 \mathrm{~m}$ depth on the surface-wave effected mooring and those of the $\mathrm{VACM}$ in $10 \mathrm{~m}$ depth on the reference mooring were about equal.

Ein Beitrag zu gleichzeitigen Messungen mit Rotor-, Flïgel- und akustischen Strömungsmessern in flachem Wasser (Zusammenfassung)

In zwei benachbarten Verankerungen waren in der Kieler Bucht vier verschiedene Strommessertypen 22 Tage lang verankert. Es handelte sich um zwei Rotorstrommesser vom Typ Aanderaa und VACM (vektormittelnder Strommesser), einen akustischen Strommesser nach Gytre sowie um einen Pendelstrommesser nach Niskin. Das VACM-Gerät mit Auftrieb in $7 \mathrm{~m}$ Tiefe wurde als Bezugsinstrument verwendet. Während der ersten 17 Tage befand sich der Auftrieb der zweiten Verankerung in $5 \mathrm{~m}$ Tiefe. Um die Verankerung den Oberflächenwellen auszusetzen, wurde der Auftrieb während der letzten 5 Tage auf 2,7 m Tiefe verlegt. Der Niskin-Flügelstrommesser wurde am meisten von der welleninduzierten Verankerungsbewegung beeinflußt. Das Gytre-Instrument zeigte den geringsten Oberflächenwelleneffekt. Die Vektorvarianz dieses Gerätes an der oberflächenbeeinflußten Verankerung in 7,4 m Tiefe war ungefähr dieselbe wie diejenige des VACM-Gerätes auf $10 \mathrm{~m}$ Tiefe in der Bezugsverankerung.

Sur des mesures simultanées faites avec des courantomètres à rotor, à ailettes et acoustique mouillés par petits fonds (Résumé)

Sur deux sites très voisins de la Baie de Kiel, quatre courantomètres de types différents ont été mouillés pendant 22 jours: Deux à rotor (Aanderaa et à «intégration vectorielle» (VACM)), un acoustique (conçu par Gytre) et un à ailettes (conçu par Niskin). Le courantomètre VACM fut utilisé sur le premier site comme instrument de référence avec une immersion de $7 \mathrm{~m}$. Sur le second site, l'immersion a été de $5 \mathrm{~m}$ pendant les 17 premiers jours de l'expérience mais ramenée à $2,7 \mathrm{~m}$ dans les 5 derniers jours pour rendre les mouillages plus sensibles aux mouvements de surface. Le courantomètre à ailettes Niskin se révèla le plus sensible aux effets dûs à la houle. Le Gytre se montra le moins sensible à ces mouvements. Les fluctuations de cet instrument à l'immersion $7,4 \mathrm{~m}$ étaient à peu près égales à celles du VACM à $10 \mathrm{~m}$, sur le site de référence. 


\section{Introduction}

The response of a current meter, suspended in an oceanographic mooring, to the flow of water past its position can differ significantly from what the data sheets of the manufacturers suggest. A number of intercomparison studies between the widely used Geodyne and Aanderaa current meters - e.g. Unesco [1969, 1974], Gould and Sambucco [1975] - as well as either of these two instruments with the later developed vector-averaging current meter (VACM) - e.g. Halpern, Pillsbury and Smith [1974], Unesco [1975], Halpern and Pillsbury [1976], Saunders [1976], Beardsley, Boicourt, Huff et al. [1977], Walden, Collins, Clay et al. [1977], Quadfasel and Schott [1979] - have been made under different environmental conditions.

From such intercomparisons it is known that all rotor instruments on moorings suspended from floatation influenced by the surface waves will show an increased speed against the currents measured from subsurface moorings, although the vector-averaging procedure of the VACM instrument greatly reduces this effect.

Besides the mooring-imposed problems, the rotor instruments have shortcomings in measurements at very low and at very high frequencies. The first shortcoming surfaces in the more recent requirements to have long-term moorings for monitoring purposes out in the ocean. For these purposes instruments without moving parts would seem preferable, especially in very large and very low currents where frequently rotors were lost or stalled at speeds below threshold.

At the high-frequency end of the spectrum the response of instruments equipped with a rotor and a current direction vane depends very much on the mechanics of these two components. For this end of the spectrum, instruments working on a small volume of water with fast response would seem much more appropriate.

In an intercomparison experiment in Kiel Bight we have compared four instruments designed for different parts of the frequency spectrum:

(1) the Aanderaa current meter (ACM)

(2) the Vector averaging current meter (VACM)

(3) the wing current meter, designed by Niskin (NWCM)

(4) the acoustic current meter, designed by Gytre (GACM).

Whereas the first two instruments have been extensively compared, the third one and the fourth one, which are both equipped with burst-sampling devices have not been widely used, so far. In our experiment we used two subsurface moorings. One of them had the floatation close to the surface to be more effected by surface waves than the other. The mooring with deeper floatation carried the VACM instrument as a reference measurement, against which we want to compare the other instruments in the following presentation.

\section{Deseription of instruments}

The ACM and the VACM are standard instruments in oceanography and widely known (cf. Dah1 [1969]). Therefore we do not present detailed descriptions but restrict ourselves to some basic specifications. For further information we refer to the literature cited. A summary of instrument specifications is given in Table 1.

\subsection{Aanderaa current meter (ACM)}

This instrument, manufactured by Ivar Aanderaa [1964], Nesttun (Bergen), Norway, measures current speed, current direction and temperature. Sensors for pressure and conductivity are installed on request.

Current speed is sensed by a Savonius-like rotor. A flat fin is attached to the pressure housing and orientates the instrument in the current direction. The direction is determined by a magnetic compass fixed inside the instrument container.

An electro-mechanical encoder samples and converts the measurements to 10 bit binary words which are recorded on $1 / 4$ inch magnetic tape. The binary signals are also transmitted to the surface by means of an acoustic transducer. An internal quartz crystal clock actuates 
the instrument at regular intervals, selectable between $30 \mathrm{~s}$ and $1 \mathrm{~h}$. The capacity of data storage is about 10000 measuring cycles.

The pressure case of CuNiSi alloy resists 2000 dbar and measures $12.8 \mathrm{~cm}$ in diameter and $55 \mathrm{~cm}$ in height, the vane size is $37 \mathrm{~cm} \times 100 \mathrm{~cm}$. Total weight in air is $280 \mathrm{~N}$.

Table 1a

Instrument specifications: sensor characteristies

\begin{tabular}{|c|c|c|c|c|}
\hline $\begin{array}{l}\text { Instrument } \\
\text { Serial no. } \\
\end{array}$ & $\begin{array}{l}\mathrm{ACM} \\
\mathbf{1 3 1}\end{array}$ & $\begin{array}{l}\text { VACM } \\
302\end{array}$ & $\begin{array}{l}\text { NWCM } \\
15\end{array}$ & $\begin{array}{l}\text { GACM } \\
-\end{array}$ \\
\hline \multicolumn{5}{|c|}{ Speed measurement } \\
\hline Sensor type & $\begin{array}{l}\text { Savonius like } \\
\text { rotor }\end{array}$ & $\begin{array}{l}\text { Savonius } \\
\text { rotor }\end{array}$ & $\begin{array}{l}\text { dual winged } \\
\text { housing and } \\
\text { inclinometer }\end{array}$ & $\begin{array}{l}2 \text {-axis } \\
\text { acoustic } \\
\text { travel time }\end{array}$ \\
\hline $\begin{array}{l}\text { Threshold } \\
\text { Range }\end{array}$ & $\begin{array}{l}2.5 \mathrm{~cm} \mathrm{~s}^{-1} \\
0-250 \mathrm{~cm} \mathrm{~s}^{-1}\end{array}$ & $\begin{array}{l}2.5 \mathrm{~cm} \mathrm{~s}^{-1} \\
0-300 \mathrm{~cm} \mathrm{~s}^{-1}\end{array}$ & $\begin{array}{l}3 \mathrm{~cm} \mathrm{~s}^{-1} \\
0-200 \mathrm{~cm} \mathrm{~s}^{-1}\end{array}$ & $\begin{array}{l}0.1 \mathrm{~cm} \mathrm{~s}^{-1} \\
\pm 150 \mathrm{~cm} \mathrm{~s}^{-1}\end{array}$ \\
\hline $\begin{array}{l}\text { Digitizing } \\
\text { resolution }\end{array}$ & $\begin{array}{l}10 \mathrm{bits} \\
0.3 \mathrm{~cm} \mathrm{~s}^{-1}\end{array}$ & 21 bits & $\begin{array}{l}8 \text { bits } \\
1 \text { to } 5 \\
\text { (depends on } \\
\text { inclination angle) }\end{array}$ & $\begin{array}{l}12 \mathrm{bits} \\
0.07 \mathrm{~cm} \mathrm{~s}^{-1}\end{array}$ \\
\hline Accuracy* & $\pm 1 \mathrm{~cm} \mathrm{~s}^{-1}$ or $2 \%$ & not specified & $\pm 0.5^{0}$ in tilt & not specified \\
\hline \multicolumn{5}{|l|}{$\begin{array}{l}\text { Direction } \\
\text { measurement }\end{array}$} \\
\hline & $\begin{array}{l}\text { trailing fin and } \\
\text { magnetic compass }\end{array}$ & $\begin{array}{l}\text { vane and magnetic } \\
\text { compass }\end{array}$ & $\begin{array}{l}\text { trailing wings and } \\
3 \text {-axis magneto- } \\
\text { meter }\end{array}$ & $\begin{array}{l}\text { 2-component } \\
\text { sensor and 2- } \\
\text { axis magneto- } \\
\text { meter }\end{array}$ \\
\hline $\begin{array}{l}\text { Digitizing } \\
\text { resolution }\end{array}$ & $10 \mathrm{bits}$ & $\begin{array}{l}21 \text { bits (component } \\
\text { sum) } \\
8 \text { bits (inst. sample) }\end{array}$ & 8 bits & 12 bits \\
\hline Accuracy* & $\begin{array}{l}2.5^{0} \\
5^{0} \text { to } 7.5^{0} \text { depending } \\
\text { on velocity }\end{array}$ & $\begin{array}{l}2.81^{\circ} \text { (inst. sample) } \\
\text { not specified }\end{array}$ & $\begin{array}{l}3^{0} \\
\pm 2^{0}\end{array}$ & $\begin{array}{l}0.1^{0} \\
\text { not specified }\end{array}$ \\
\hline \multicolumn{5}{|l|}{$\begin{array}{l}\text { Temperature } \\
\text { measurement }\end{array}$} \\
\hline Sensor type & thermistor & thermistor & - & $\mathrm{PT}-100$ \\
\hline Range & $-2.46^{\circ} \mathrm{C}$ to $21.4^{\circ} \mathrm{C}$ & not specified & - & $-2^{\circ} \mathrm{C}$ to $18^{\circ} \mathrm{C}$ \\
\hline Digitizing & $10 \mathrm{bits}$ & 21 bits & - & 12 bits \\
\hline Accuracy* & $0.05^{0} \mathrm{C}$ & $0.01^{\circ} \mathrm{C}$ & - & not specified \\
\hline
\end{tabular}

* as specified by manufacturer

Abbreviations: ACM-Aanderaa current meter (CM), VACM-vector averaging CM, NWCMNiskin wing CM, GACM-Gytre acoustic CM

Table $\mathbf{1 b}$

Instrument specifications: data sampling and recording scheme during experiment

\begin{tabular}{l|llll} 
Instrument & ACM & VACM & NWCM & GACM \\
\hline Sampling mode & continuous & continuous & bursts & bursts \\
Burst duration & - & - & $10.56 \mathrm{~s}$ & $7.5 \mathrm{~s}$ \\
No. of sample/burst & & & 8 & 15 \\
Recording interval & $2 \mathrm{~min}$ & $0.9375 \mathrm{~min}$ & $15 \mathrm{~min}$ & $5 \mathrm{~min}$ \\
\hline
\end{tabular}




\subsection{Vector averaging current meter (VACM)}

The instrument has been developed at Woods Hole Oceanographic Institution and was manufactured by AMF, Sea Link Division, Alexandria, Virginia, USA. It measures current speed, direction and temperature.

Current speed and direction are measured by a Savonius rotor and a vane mounted along the vertical axis on the lower end of the instrument case. The vane heading related to the housing is sensed by a vane follower through magnetic coupling. A magnetic compass provides the orientation of the instrument against magnetic north. The direction measurement is accomplished by combining the vane and compass readings. Temperature is sensed by a thermistor.

Every eighth of a rotor turn the direction is determined and converted internally into Cartesian coordinates (north end east). Thus, in a one knot current, more than 38000 samples an hour are taken. The components are added and at the end of every recording interval, which can be chosen as $56.25 \mathrm{~s}$ and multiples thereof, the sum of the eastward and the sum of the northward components are stored on magnetic tape cassette.

Together with the sum of the computed components five other parameters are recorded: the total rotor count, an instantaneous compass heading, an instantaneous vane heading, temperature and a time word provided by a crystal controlled clock. The data are recorded on a model 610 four track digital cassette recorder, manufactured by Sea Data Corporation. $11 \times 10^{6}$ bits or $\approx 50000 \mathrm{VACM}$ cycles can be stored on a Philips type magnetic tape cassette.

The $19 \mathrm{~cm}$ diameter pressure case of anodized aluminium is designed for $6000 \mathrm{~m}$ operating depth. The instrument has a total length of about $2 \mathrm{~m}$, its weight in air is $730 \mathrm{~N}$.

A complete description of the VACM speed calibration and data recording techniques is given by $\mathrm{McCullogh}[1975]$.

\subsection{Niskin wing current meter (NWCM)}

The instrument is manufactured by General Oceanics Inc., Miami, Florida, USA. Model 6011 is a drag-force current meter, measuring and recording current speed and direction. Model 6011-T is additionally equipped with a temperature senor.

A cylindrical pressure case with two trailing fins is negatively buoyant and hangs vertically downward from a mounting swivel when suspended in still water. A current causes the instrument to incline from the vertical in the down-current direction.

The magnitude and direction of this tilt is measured by four sensors - an inclinometer and three Hall effect sensors. Each Hall effect sensor generates a voltage proportional to the component of the earth's magnetic field along its sensitive axis. The readings of the four sensors are combined to compute current speed and direction.

The instrument operates under control of a quartz crystal timer, which may be set to sampling intervals between $7 \mathrm{~s}$ and $1 \mathrm{~h}$. It is also possible to use burst sampling at these intervals with $4,8,16$ or 32 readings per burst.

At each sampling interval, readings of all four sensors are digitized to 8 bits and combined together with a time code and the instrument's serial number to a 64 bit serial word.

Data are stored on a Philips type magnetic tape cassette by use of a special designed two track digital cassette recorder with a capacity of 20000 cycles.

At the time of our experiment the manufacturer requested that users specified the anticipated speed range and then the fin size was adjusted to provide optimum sensitivity and resolutions. In our case the vane was made for higher speeds than finally occurred in the measured region. The anodized aluminium pressure housing (diameter $10.5 \mathrm{~cm}$, length $51.5 \mathrm{~cm}$ ) is rated to $6000 \mathrm{~m}$ safe working depth. In air the weight of the instrument is $90 \mathrm{~N}$.

\subsection{Gytre acoustic current meter (GACM)}

This instrument has been developed by T. Gytre at the Chr. Michelsens Institute, Bergen, Norway, and was also manufactured there (cf. Gytre [1976], Collar and Gwilliam [1977]). It is equipped with a two component acoustic current sensor, a compass and sensors for temperature and pressure. 
Delivered in January 1976, the instrument was one of the first working current meters operating on an acoustic principle. Current velocity is measured in components along two orthogonal axes. For each axis two opposite ultrasonic transducers, separated by a distance of about $15 \mathrm{~cm}$ are pulsed simultaneously. Each then receives the signal transmitted by the other. The difference in travel time between the two acoustic pulses moving with and against a component of the current vector is used to determine the current speed along this axis. With a time resolution capability of $\approx 10^{-10}$ s the sensor has a very low velocity threshold and resolution of $\approx 1 \mathrm{~mm} \mathrm{~s}$.

The current components are measured relative to the housing. To obtain the current direction relative to magnetic north the instrument is equipped with a fluxgate compass, which measures two components of the earth's magnetic field relative to the housing. Temperature is sensed by a platinum resistance thermometer, a piezoresistive transducer is provided for pressure measurement.

The six analog sensor signals are sequentially sampled and digitized to 12 bit binary words by a data acquisition unit containing sample and hold, multiplexer, $A / D$ converter and a programmable crystal controlled timer. Sampling intervals can be selected between 5 seconds to 2560 minutes. At this rate also burst sampling with 2 to 15 samples per burst is possible, the individual samples at intervals from $0.5 \mathrm{~s}$ to $15 \mathrm{~s}$. In continuous mode the instrument samples every $0.5 \mathrm{~s}$.

With every sampling cycle a 16 bit counter is incremented and stored together with digitized sensor data on a Sea Data 610 cassette recorder with a capacity of $10^{7}$ bits or 64000 cycles. The instrument is housed in a $17 \mathrm{~cm}$ diameter cylindrical pressure case of stainless steel, designed for 1000 dbar. Total length is about $1 \mathrm{~m}$, weight in air $350 \mathrm{~N}$. Recent versions of the current meter are available with several other sensor configurations, recorders and pressure cases.

\section{The experiment}

For our current meter intercomparison experiment a location within the protected area of the special research project of Kiel University (SFB 95) has been chosen. The mooring locations, depth $14 \mathrm{~m}$ to $16 \mathrm{~m}$, are given in Fig. 1. They were situated near Boknis Eck at

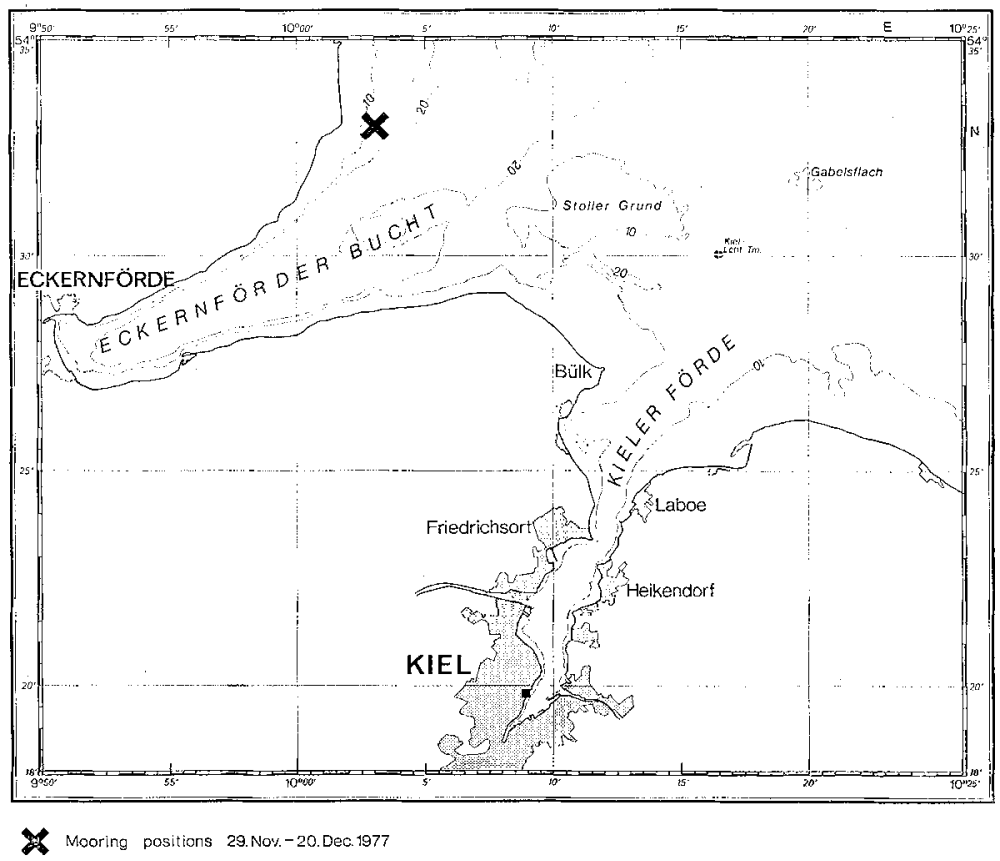

Fig. 1. Location of the current meter experiment in southern Kiel Bight 
the northern entrance of Eckernförde Bight in the southern Kiel Bight (Fig. 1). As near bottom current observations by Rumohr [1979] show that current speeds usually are less "than $20 \mathrm{~cm} \mathrm{~s}^{-1}$. At least near the bottom currents are guided by the topography. The flow is either NE or SW along the slope of the bight which increases with about $1 \mathrm{~m} / 100 \mathrm{~m}$ towards SE.

\subsection{The mooring configuration}

Two single-legged moorings were deployed in water depths between $14 \mathrm{~m}$ and $16 \mathrm{~m}$ near

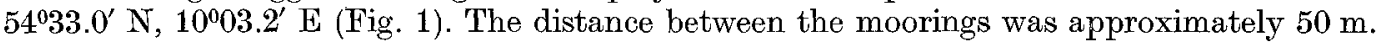
The moorings consisted of a $350 \mathrm{~kg}$ groundweight, an $8 \mathrm{~mm}$ diameter steel cable with the current meters attached to and a steel ball $0.8 \mathrm{~m}$ in diameter as buoyancy. The ball was connected with a $16 \mathrm{~m}$ long $10 \mathrm{~mm}$ diameter Perlon line to a little marker buoy which was used for recovery. The net buoyancy of the mooring yielded $840 \mathrm{~N}$.

The first set of two moorings was deployed on 29 November 1977 by F.K. "Littorina" and recovered on 16 December (Phase I), the second set was deployed 16 December after changing the recording tapes and cassettes and recovered 20 December (Phase II). Originally it was planned to have both phases of equal length. But due to ship schedules the first leg had to be extended, thus shortening the second phase. In the first phase, both moorings were subsurface moorings, in the second phase, mooring 225, with the GACM, NWCM. and ACM, had the top float close to the surface to study wave-induced effects on these instruments.

The distribution of instruments is presented in Fig. 2 and Table 2.
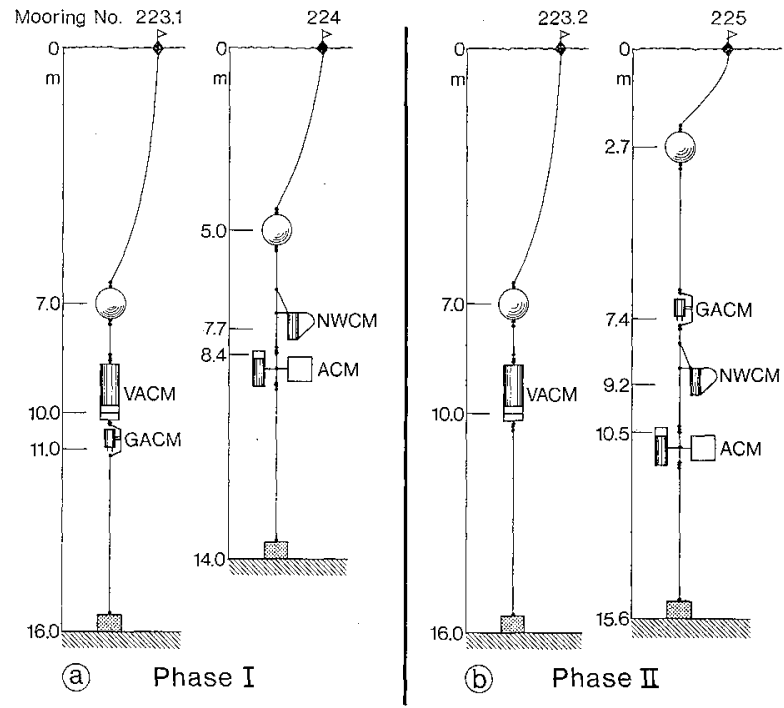

Fig. 2. Mooring configuration during Phases I and II. Abbreviations: ACM-Aanderaa current meter (CM), VACM-vector averaging CM, NWCM-Niskin wing CM, GACM-Gytre acoustic CM

\subsection{Meteorological and hydrographic conditions}

Time series of wind speed and direction, based on standard synoptic weather observations at Kiel lighthouse at 0600 and 1800 GMT are plotted in Fig. 3. The distance to the mooring array is less than $15 \mathrm{~km}$ and the data can therefore be taken to represent the conditions at the location of the intercomparison experiment.

During the first part of Phase I wind speeds were less than $7.5 \mathrm{~m} \mathrm{~s}^{-1}$ with the direction fluctuating between $\mathrm{N}$ and NE. At 7 December a strong wind phase began, with a speed of $14 \mathrm{~m} \mathrm{~s}^{-1}$, staying about constant over four days. During this time the direction was steady ESE. After this storm period the wind changed direction to $\mathrm{SW}$ with speeds around $6 \mathrm{~m} \mathrm{~s}^{-1}$ until the end of Phase II. 
Table 2

Distribution of current meters during Phases I and II.

For further details see Fig. 2. Abbreviations: see Table 1

Phase I 29. 11. - 16. 12. 1977

Phase II 16. 12. - 20.12.1977

\begin{tabular}{l||c|r||r|r}
\hline \hline \multicolumn{1}{c||}{ Mooring no. } & 223.1 & 224 & 223.2 & 225 \\
\hline $\begin{array}{l}\text { Depth of } \\
\text { buoyancy }\end{array}$ & $7.0 \mathrm{~m}$ & $5.0 \mathrm{~m}$ & $7.0 \mathrm{~m}$ & $2.7 \mathrm{~m}$ \\
\hline \hline $\begin{array}{l}\text { Instruments } \\
\text { depth }\end{array}$ & VACM $10.0 \mathrm{~m}$ & NWCM $7.7 \mathrm{~m}$ & VACM $10.0 \mathrm{~m}$ & GACM $7.4 \mathrm{~m}$ \\
\hline GACM $11.0 \mathrm{~m}$ & ACM $8.4 \mathrm{~m}$ & & NWCM $9.2 \mathrm{~m}$ \\
\hline Water depth & & & & ACM $10.5 \mathrm{~m}$ \\
\hline
\end{tabular}

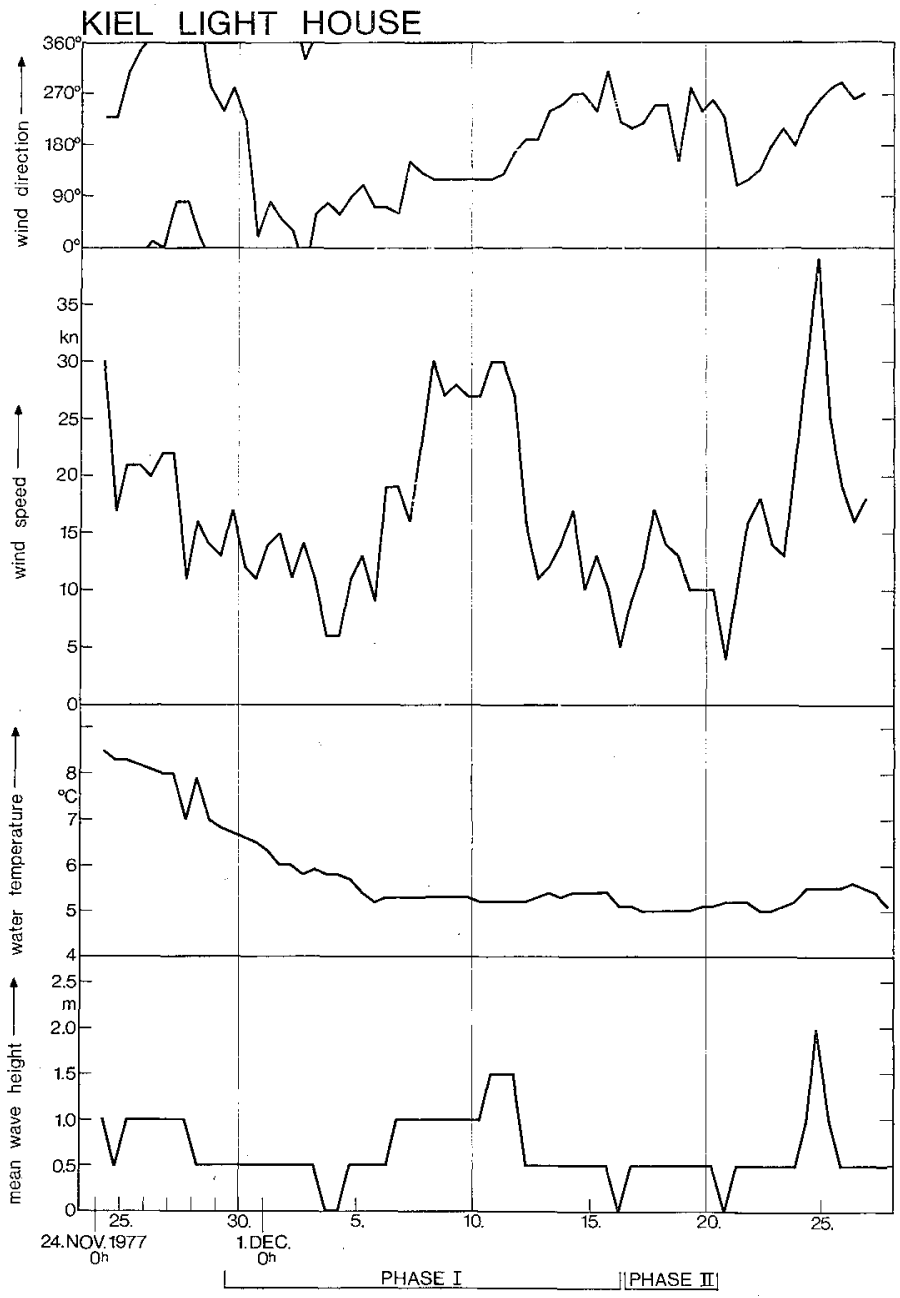

Fig. 3. Meteorological conditions and sea state at Kiel Lighthouse during the experiment 
Fig. 3 also shows the mean wave height at this position. It is directly related to the wind speed and does not exceed $2 \mathrm{~m}$. These relative low values ean by explained by the short distance to the coast over which no swell can develop.

The hydrographic regime of the observational area in a first approximation can be regarded as a two layered sea. The surface layer consists of low salinity Baltic water while high salinity water from the North Sea can be found in the bottom layer. The depth of the halocline is highly variable, being on the average around $10 \mathrm{~m}$. But especially during times of rapid wind changes the depth of the halocline may change up to $8 \mathrm{~m}$ within a few hours (Geyer [1964]). Typical velocity profiles in the Kiel Bight frequently show outflow of water masses from the inner Baltic Sea at the surface or inflow through the Belt Sea at the surface, the largest vertical shear being in the halocline. Unfortunately no hydrographic profiles have been made during the time of the experiment. But some indications for a vertical movement of the boundary between Baltic and. North Sea water can be found in the temperature time series of the moored instruments (Fig. 4). On 5 December the Aanderaa current meter in $8.4 \mathrm{~m}$ depth and the VACM $(10.0 \mathrm{~m})$ show a rapid increase of more than $1{ }^{\circ} \mathrm{C}$ in temperature. During this time the surface temperature (Fig. 3) decreases steadily and therefore this increase must be due to an uplifting of the halocline and thermocline.
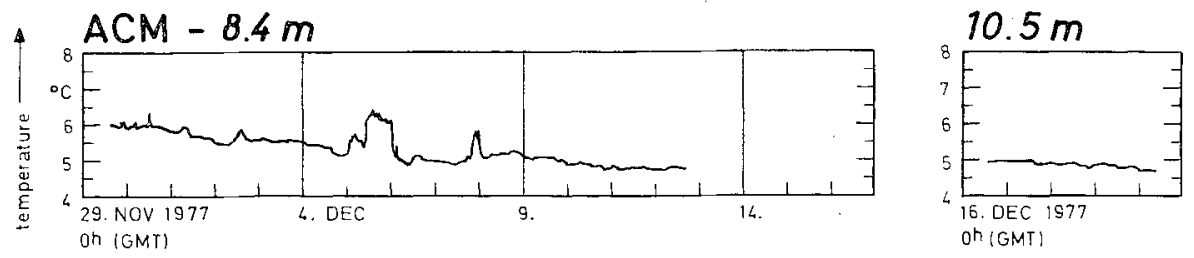

\section{GACM - $11.0 \mathrm{~m}$}
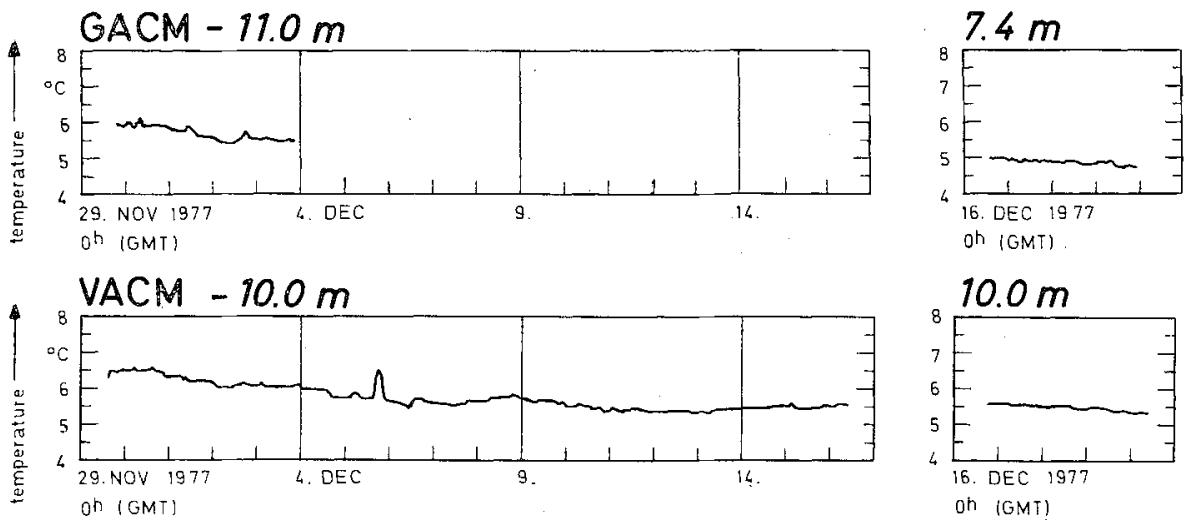

Fig. 4. Half hourly averaged time series of temperature records from Phases I and IL. Note the NWCM was not equipped with a temperature sensor

\section{Instrument performance and data reduction}

The original records of current meters used in the intercomparison were processed in different ways, due to the different recording and calibration procedures. Half hourly averages have been calculated in order to have the same basis for the statistical intercomparison. Most of the computing was done at the PDP 11 of the Institut für Meereskunde Kiel (IfM). Details about the decoding, calibration and editing of the raw data are given below separately for each instrument.

\subsection{Aanderaa current meter}

The whole data processing was done at the IfM. Less than $0.1 \%$ of the raw data were not decodable and therefore later interpolated. Calibration of speed and direction was done with the manufacturer's calibration curves. 
356 values $(2.7 \%$ ) were obviously erroneous and have been linearily interpolated between neighbouring values. Due to limited data storage on the recording tape the current meter recorded only during the first 13 days of Phase I. On 16 December a new tape had been loaded and Phase II is fully covered.

\subsection{Vector averaging current meter}

Raw data were read from cassettes on a Sea Data model 12 reader and transferred to 9-track magnetic tape. Further processing was done on a PDP 11/45, using directions given by McCullogh [1975] for calibration. Only few data (less than $0.5 \%$ ) were spiky and had had to be interpolated between neighbouring values.

\subsection{Niskin winged current meter 6011}

The cassette tape was sent to General Oceanics Inc. for processing. A 9-track computer tape with the decoded values of the measured parameters, tilt and three variables from the Hall effect sensors, was provided. Calibration of speed and current direction was then done at the IfM according to the manufacturer's calibration instructions. The inclinometer value would be directly converted into current speed by using the calibration curve for the particular instrument. To obtain the direction of current the Hall sensor magnetometer readings had to be combined with the inclinometer reading.

$77 \%$ of the single tilt measurements showed a negative current which could not in all cases be explained by surface wave induced mooring and instrument motion. Taking the results of another intercomparison experiment with VACM and Niskin current meters in deep water (Bonde [1978]) it was assumed that the instruments trim was off which lead to the negative bias.

The tapes were reprocessed using different offsets. Shifting the offset by one increment, which corresponds to an instrument tilt of $0.42^{0}$, leads to about $5 \mathrm{~cm} \mathrm{~s} \mathrm{~s}^{-1}$ increase in speed. The fraction of negative speeds for different offset angles is presented in Table 3.

\section{Table 3}

Fraction of negative-current speed measurements in \% for different trim corrections for Niskin wing current meter.

Manufacturer's instruction $\alpha=0.42^{\circ}$

\begin{tabular}{c|c|c|c|c|c|c} 
offset angle $\alpha$ & $+0.42^{0}$ & $0.0^{0}$ & $-0.42^{0}$ & $-0.84^{\circ}$ & $-1.26^{0}$ & $-1.68^{0}$ \\
\hline neg. speed values & $77 \%$ & $55 \%$ & $31 \%$ & $14 \%$ & $10 \%$ & $8 \%$
\end{tabular}

For further processing an offset of $\alpha=-0.84^{\circ}$ has been used, thus allowing $14 \%$ negative current speeds (Fig. 7), but obtaining plausible mean current speeds. Of course, such an assumption cannot replace a proper calibration. The negative currents appear all in the period between 5 and 10 December 1977 when the strong ESE storm was blowing and may therefore be a result of increased mooring motion. For the following consideration we took the absolut values of speed as shown in Fig. 7. To calculate the current direction one needs the magnetometer data as well as the inclinometer readings. Therefore the current directions cannot be used during times of erroneous (negative) tilt measurements, as it occurred during this time.

Outside this period the computed speeds showed some similarities to the other instrument recordings and it was found to be useful to continue the analysis of the Niskin current meter data and not to stop at this stage.

However, at this point some general remarks about the accuracy of the Niskin current meter shall be made. The accuracy of the tilt measurement as given by the manufacturer is $\delta \theta= \pm 1 / 2$. This corresponds to an accuracy of $\delta v= \pm 5.6 \mathrm{~cm} \mathrm{~s}^{-1}$ in speed in the low velocity range and of $\delta v= \pm 2 \mathrm{~cm} \mathrm{~s}^{-1}$ at higher speeds. Fig. 5 shows the calibration curve speed versus tilt given by General. Oceanics and the computed accuracy $\delta v$ at different speeds. 
It can be seen that only in a speed range between $40 \mathrm{~cm} \mathrm{~s}^{-1}$ and about $130 \mathrm{~cm} \mathrm{~s}^{-1}$ the accuracy (and resolution) is in the order of $1 \mathrm{~cm} \mathrm{~s}^{-1}$ while at low and very high speeds deviations up to $5.5 \mathrm{~cm} \mathrm{~s}^{-1}$ occur. The same holds for the instruments trim which can only be shifted by $4.5 . \mathrm{cm} \mathrm{s}^{-1}$ increments.

These limitations of the instrument in measuring currents: have to be kept in mind during the following discussion.

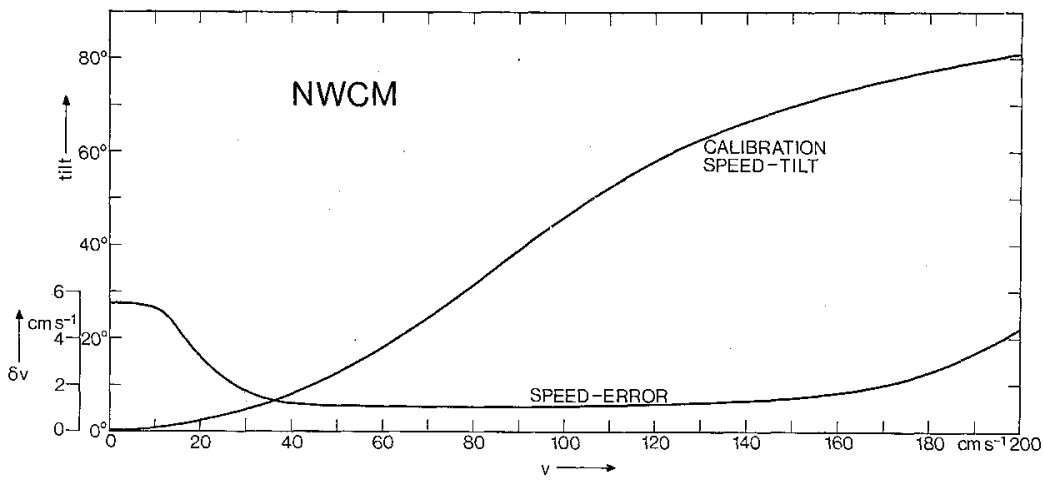

Fig. 5. Calibration and speed error curves for the NWCM

\subsection{Gytre acoustic eurrent meter}

In the same way as for the VACM the cassettes with GACM data were read on a Sea Data model 12 reader connected to a buffered 9-track magnetic tape unit. The 9 track tape files were decoded to obtain raw data. Calibration values given by the manufacturer were used for further processing.

Records from Phase I showed only for the first four days plausible values. A sharp break then occurs with nearly randomly distributed values for subsequent data of all sensors. Phase II was completely decodable. We relate the breakdown during Phase I to problems with the power supply. The capacity of the battery package is kept a little short compared to power consumption. So it might be possible that voltage fell below the limit for proper operation of the $\mathrm{A} / \mathrm{D}$-converter if the battery storage time limit was exceeded.

No missing or wrong value was found in the data of the cycle counter. However, for the evaluation of the burst sampling the counter should be incremented with the beginning of a burst and not with each individual sample. The counter does not start from zero when power is switched on and the first records on cassette are often erroneous and suppressed during cassette reading and decoding procedure. As a proper identification of the bursts within the data set was therefore missing we chose the unusual behaviour of the temperature sensor to synchronize the burst samples. The curve of temperature data plotted against cycle counter shows a sawtooth like shape, with peaks appearing every 15 th cycle and so marking the begin of a burst (Fig. 6). Sawtooth amplitude corresponds to typical $0.1{ }^{\circ} \mathrm{C}$

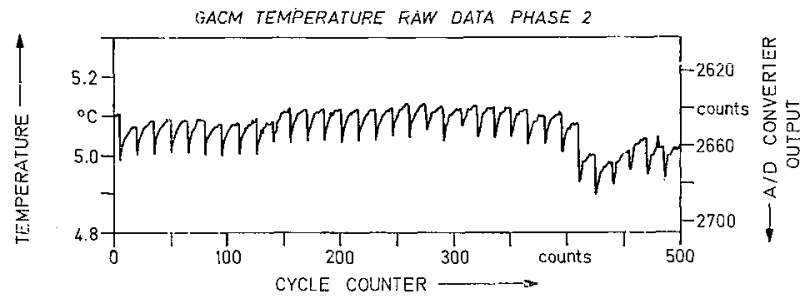

Fig. 6. Example for the temperature raw data recorded by the GACM. Note that the cycle counter does not indicate pauses between bursts. For details see Table 1 and text 
variations in temperature. This phenomenon might be explained by current heating of the Pt-100 platinum resistance sensor during measuring time of one burst $(7.5 \mathrm{~s})$. The sensor is operated in a d.c. bridge circuit which causes a current of $4 \mathrm{~mA}$ flowing through the sensor and therefore a power dissipation of $1.6 \mathrm{~mW}$. Between the bursts power is switched off and the sensor gains ambient temperature again. Of course, drift of the amplifier circuit might produce similar effects.
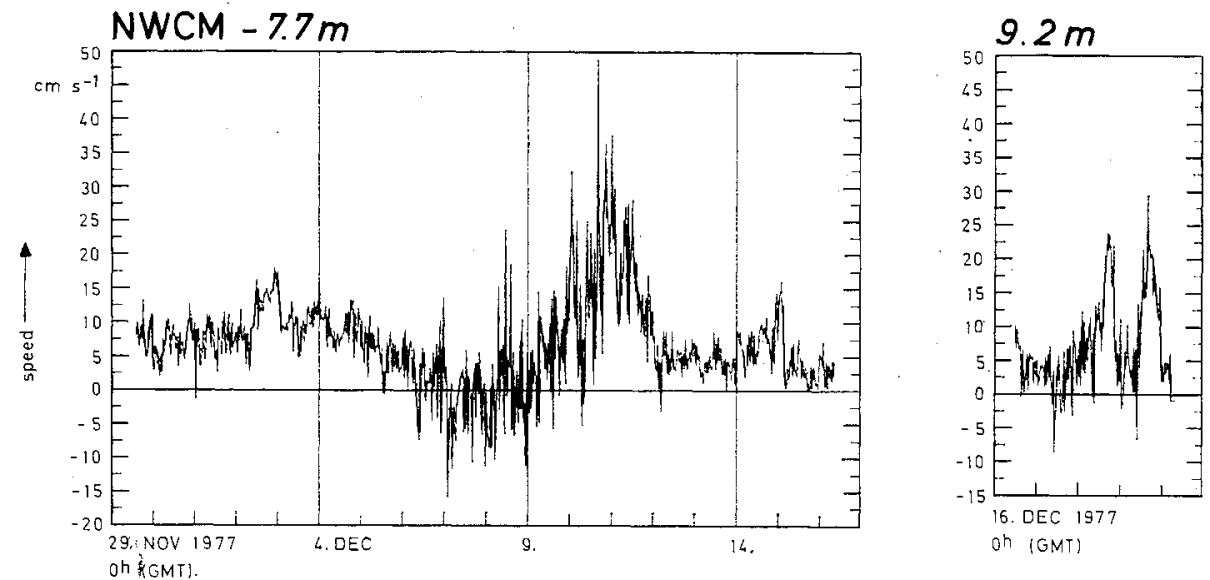

Fig. 7. NWCM speed data after correction for tilt off-set. The remaining $14 \%$ of RSPD $<0$ were rectified for the following considerations

One component of the fluxgate magnetometer compass showed constant values of maximum reading for both periods of the experiment. Therefore the compass readings were not evaluated. Instead we have performed a co-ordinate transformation by a fixed rotating angle in order to obtain best agreement with the VACM-results.

When discussing the results obtained with this instrument the prototype character of this early version should be considered. Most of the problems observed by us are known to the manufacturer and have been fixed in later instruments.

\section{Instrument comparison}

In case of identical, closely spaced measuring devices, deviating observational results in field experiments may be caused by physical differences of the ocean and/or mooringmotion-induced errors. To avoid too large vertical separations of the instruments during Phase I of the intercomparison experiment, the units were arranged closely together on two moorings of equal length of $9 \mathrm{~m}$ (mooring 223.1 and 224). However, due to environmental restrictions, the two strings were launched at locations, which had water depths differing by $2 \mathrm{~m}$. As shown in section 3.3 , at least one period occurred during the experiment when the intermediate thermohaline layer moved vertically through the array. Therefore, one must carefully check the structure of the water column before comparing vertically separated instruments.

In contrast to Phase I, where the subsurface buoys were clearly below a significant influence of surface wave action - at least until 6 December - we chose different mooring lengths during Phase II exposing mooring 225 more to near-surface effects. The philosophy was to compare results from records affected by mooring-motion with a reference station supposedly unaffected by contaminations (mooring 223.2). Half hourly averaged validated time series from all instruments are presented in Fig. 8.

Because of possible spatial and temporal gradients in the current field we have considered. only daily mean values for direct intercomparisons of instruments (Fig. 9). During the low- 

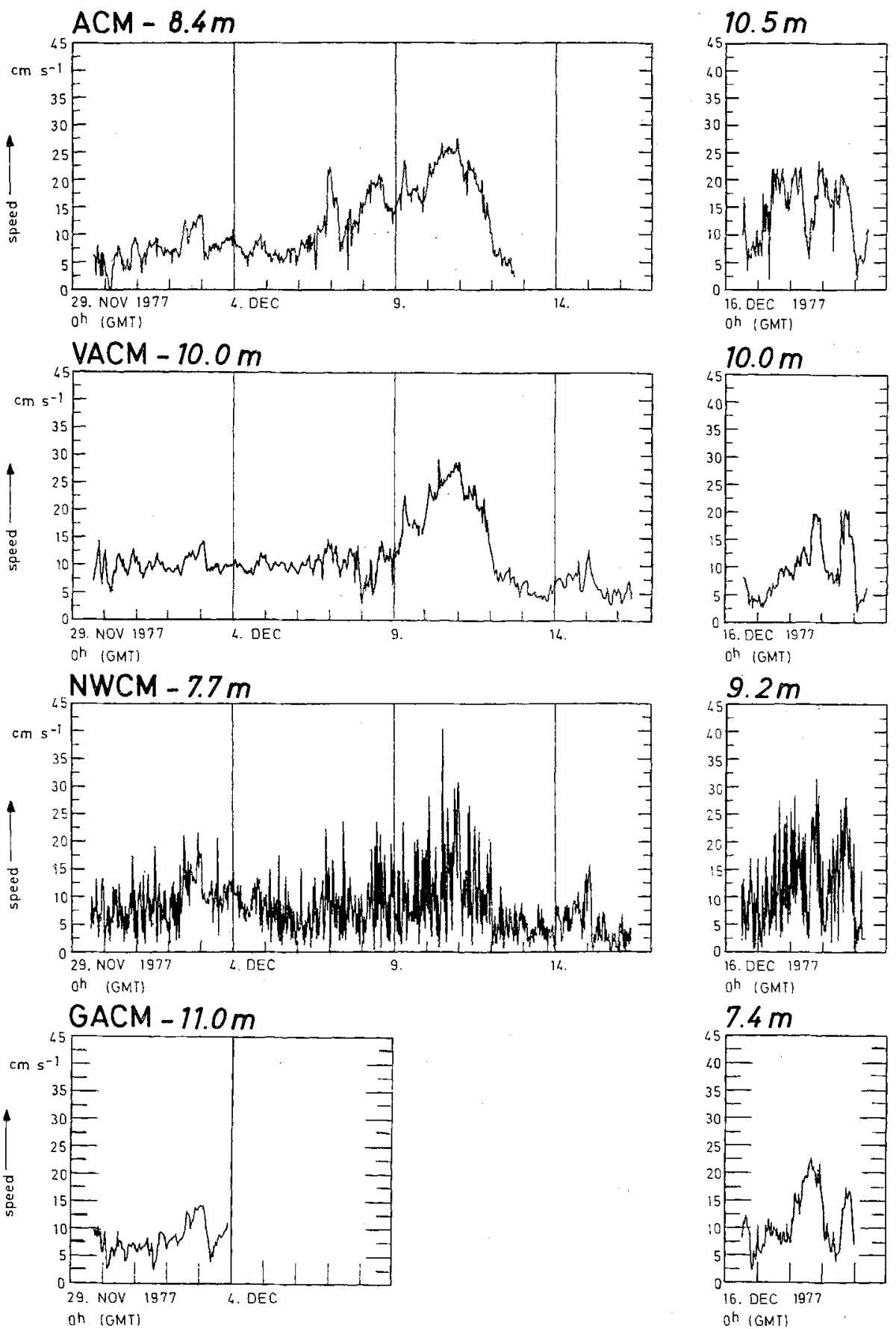

Fig. 8a. Half hourly time series of speed data. Because of malfunction of the compass device of the GACM we have adjusted the direction according to the VACM 

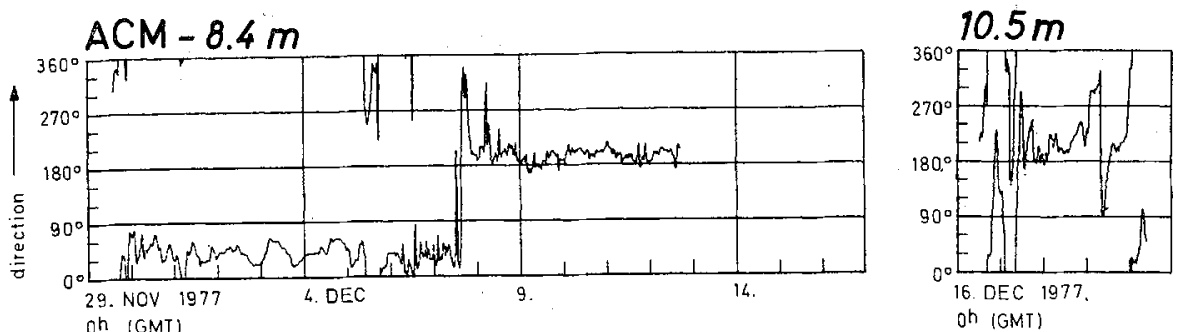

VACM $-10.0 m$

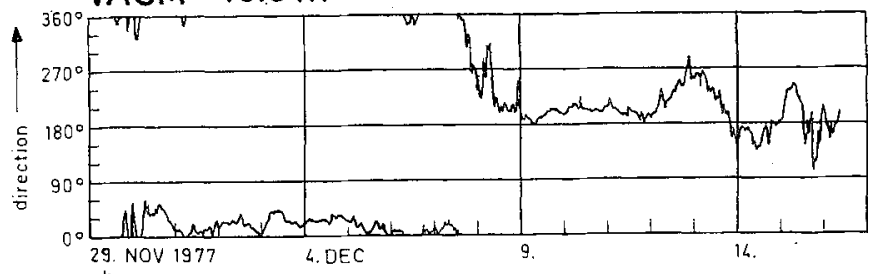

oh (GMT)

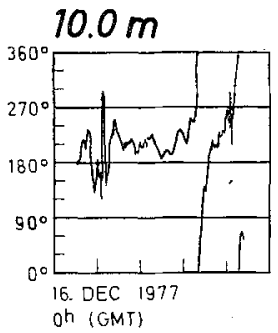

NWCM $-7.7 m$

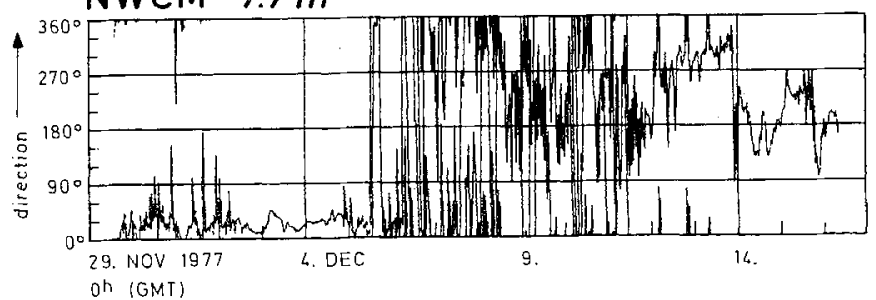

$9.2 m$

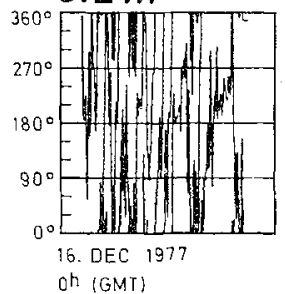

GACM $-11.0 m$
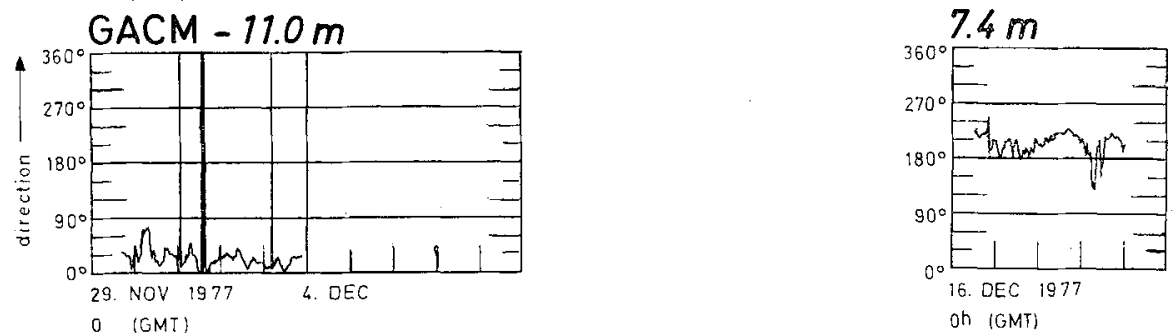

Fig. 8b. Half hourly time series of direction data. Because of malfunction of the compass device of the GACM we have adjusted the direction according to the VACM

speed regime at the beginning of Phase I all four meters gave remarkably equal results. After 5 December, NWCM showed a systematic decrease in speed. Lowest values were reached during 7 December. At the end of Phase $I$ the NWCM approached the VACM means again. This mysterious decrease of the NWCM speed might be explained by some artificial weight, e.g. sea weed disturbing the instrument's trim. On the other hand the coincidence with the onset of the storm and the decrease of the speed together with the occurrence of instantaneous negative speed values (Fig. 7) led us to the conclusion that the instrument started pendulum motions, induced by wave actions which do not seem to be sufficiently removed through burst sampling. During the stormy Phase II when the subsurface buoy was explicitely exposed to waves we observe a comparable trend to lower speed values with occasionally negative speeds.

On 8 December we find a remarkable $50 \%$ difference between the Aanderaa and the VACM. A possible explanation can be given by the temperature record in Fig. 4 where we find in the Aanderaa trace a sudden increase of about $1^{\circ} \mathrm{C}$. We interprete this event as a transition 
of the halocline associated with large current shear which does not allow to compare the current meter records from this day. We also realize that in Phase II the Aanderaa and Gytre meter speeds are about 20\% higher than the VACM speeds. In case of the Aanderaa which was approximately at the same depth as the VACM we would expect a bias due to mooring motion. This is confirmed by the high vector variance (Fig. 9 below) on 17 and 19 December whereas the considerably lower value on 18 December remains unexplained. The Gytre instrument, however, was closer to the surface and may well have measured higher speeds. As we discuss later, its vector variance, in opposition to its speed, was significantly smaller than the vector variance of the Aanderaa:
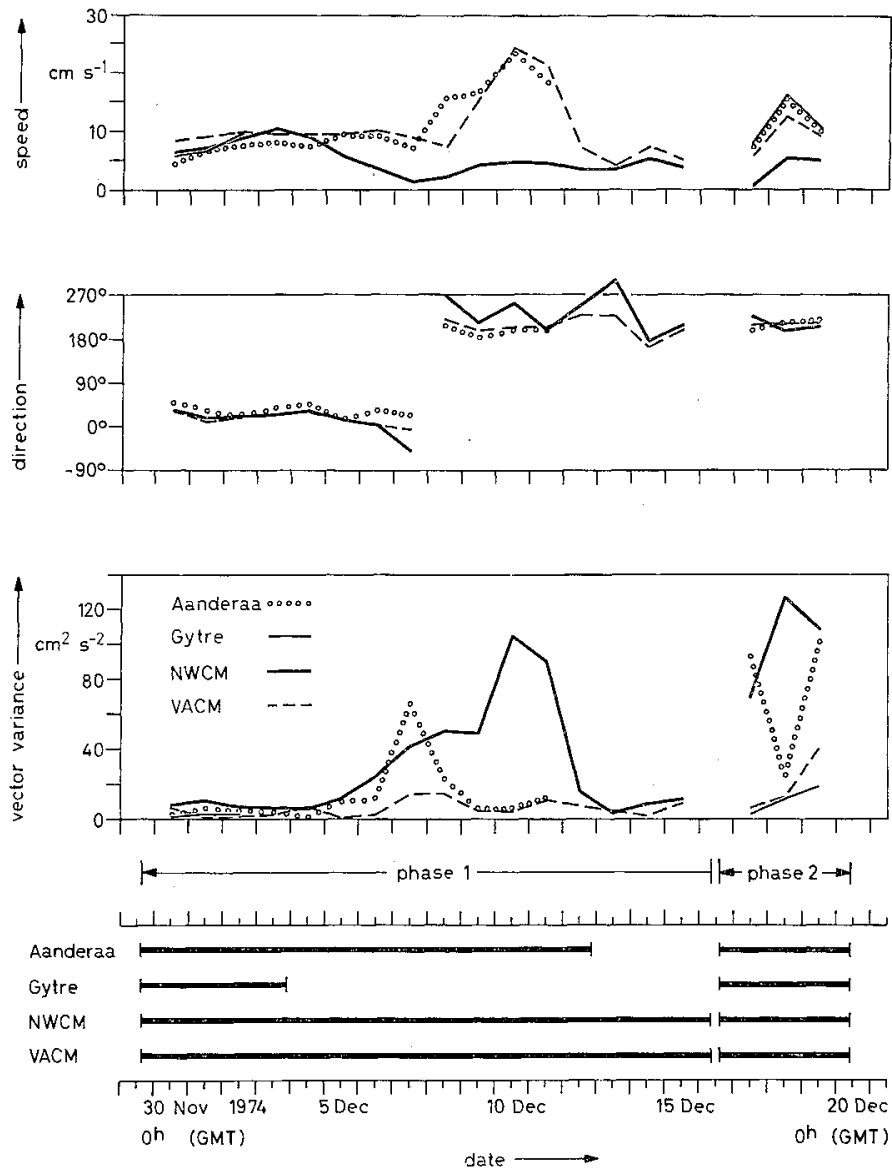

Fig. 9. Daily mean values of speed, direction and vector variance together with the instruments' chronology

Fig. 9 middle shows daily mean directions of the Aanderaa, NWCM and VACM. The NE current system is well reproduced in all records until 6 December. After the storm reached its maximum the current regime turned by roughly 180 degrees until the end of the experiment. All three instruments showed reasonable agreement in their direction records. The NWCM signal was noisier than the Aanderaa and the VACM. Because of the mentioned compass problems with the Gytre instrument we had to omit the direction of this instrument.

Coming back to the vector variance diagram (Fig. 9 below) we find that after a calm weather period with good agreement of all four instruments the NWCM maximum on 10 December occurs simultaneously with the maximum wave height at Kiel lighthouse. Assuming that 
this high variance, being $0(10)$ higher than the VACM value, was caused by wave action at the floatation in $5 \mathrm{~m}$ depth, we can interprete similar high values during Phase II when surface wave motions were induced through the $2.7 \mathrm{~m}$ deep floatation. It is especially worth mentioning that during Phase II the vector variances of the shallow Gytre $(7.4 \mathrm{~m})$ suspended from a wave-influenced mooring, and the deeper VACM $(10 \mathrm{~m})$ on a more stable mooring were of the same order. This behaviour indicates the GACM's ability of eliminating contaminations caused by surface waves induced mooring motion. While we tend to explain

$A C M-8.4 m$

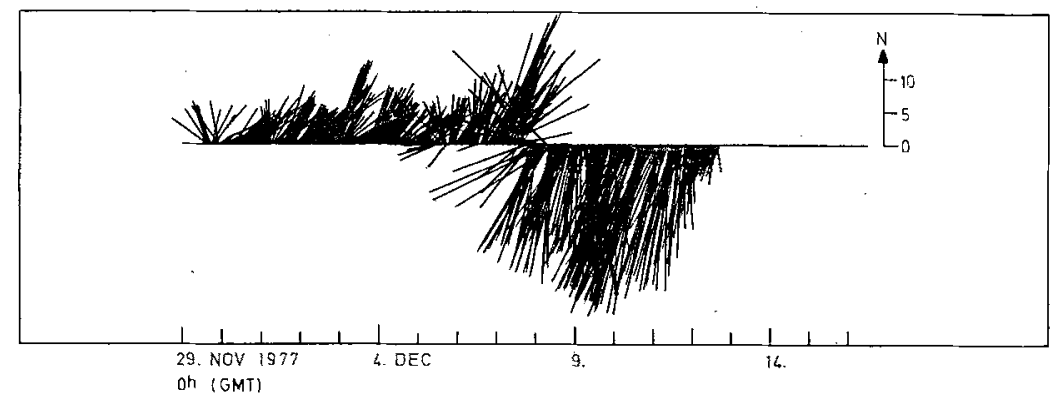

GACM $-11.0 m$

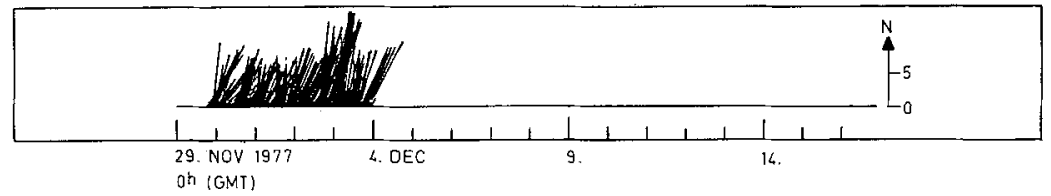

NWCM $-7.7 m$

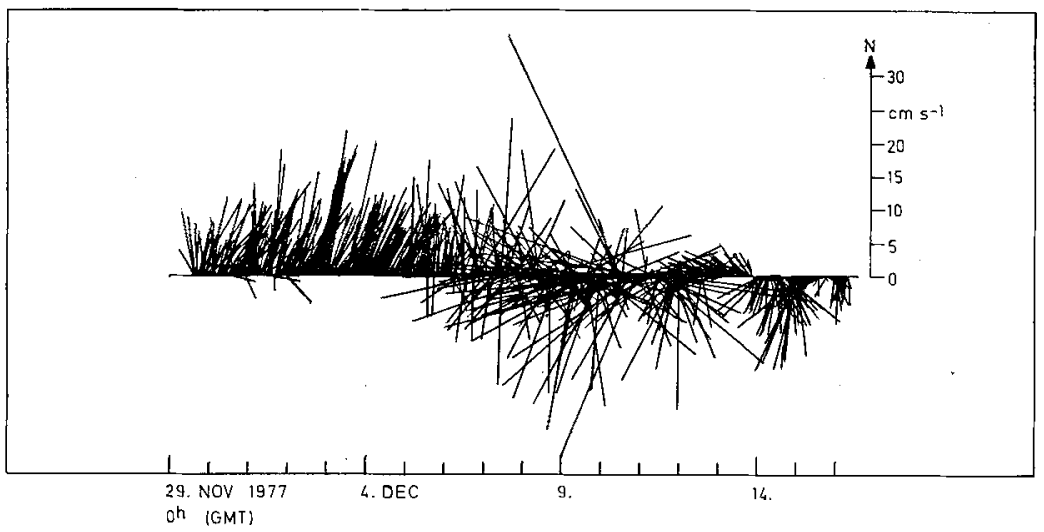

VACM $-10.0 \mathrm{~m}$

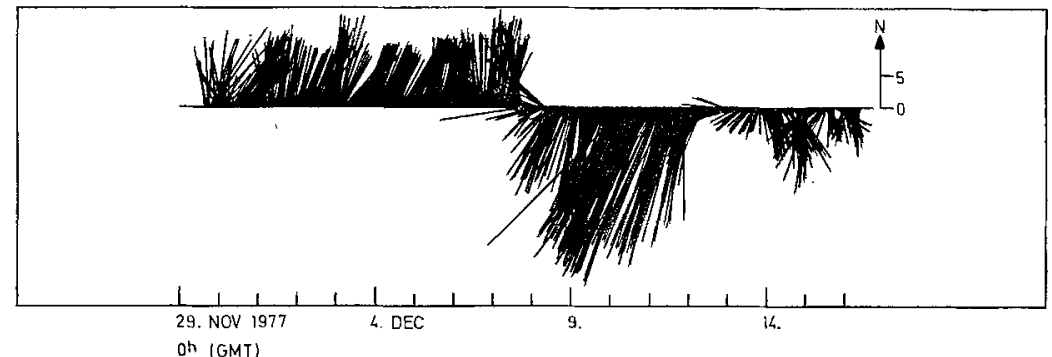

Fig. 10a. Hourly vector time series of recorded data for Phase I 


\section{$\mathrm{ACM}-10.5 \mathrm{~m}$}

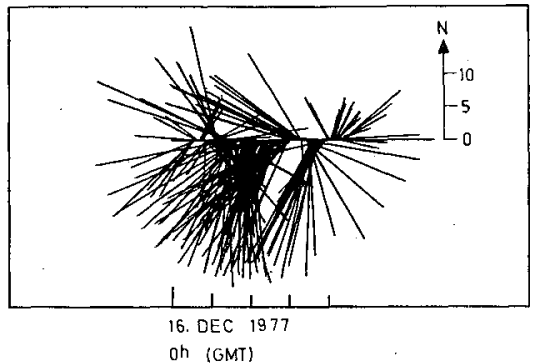

NWCM $-9.2 m$

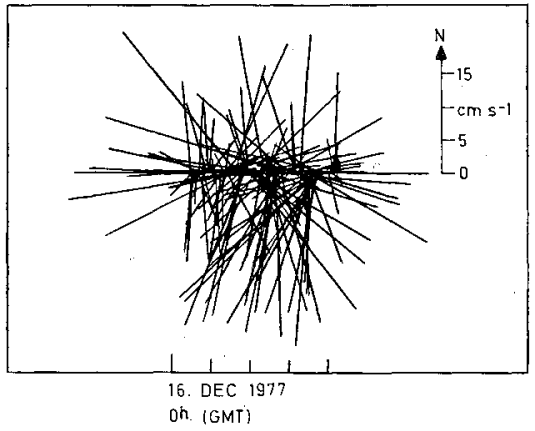

VACM $-10.0 m$

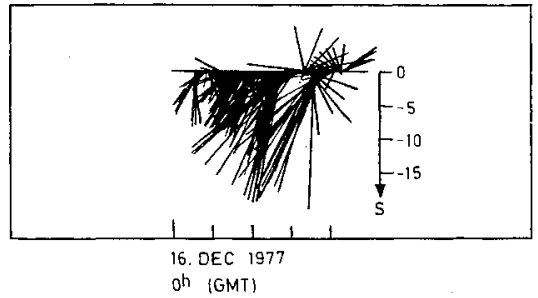

GACM $-7.4 m$

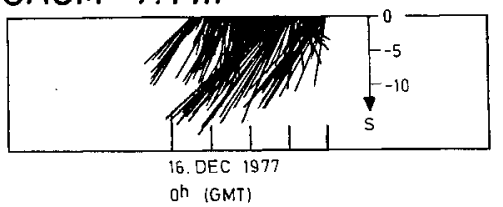

Fig. 10b. Hourly vector time series of recorded data for Phas e II

the Aanderaa maximum in vector variance on 7 December by the interface passing through the array, we had expected high values during Phase II. These high levels can be explained by rectification processes caused by the great inertia of the instrument's vane (cf. Saunders [1976]).

The vector time series in Fig. 10 represent hourly values of 30 min-averages of the original data. They show the general turning of the current system on $7 / 8$ December superim- 
posed by a variety of high frequency non-coherent motions. The high vector variance of the NWCM, already seen in Fig. 9 below, is demonstrated here in form of nearly randomly distrib. uted vector arrows after 6 December and during the whole second phase. In both cases the meter was exposed to surface wave motion.

\section{Summary and conclusions}

Four cúrrent meters were deployed in two moorings closely spaced in an intercomparison experiment in the Kiel Bight in $16 \mathrm{~m}$ depth from 29 November til 20 December, 1977. One mooring with the buoyancy float in $7 \mathrm{~m}$ depth with a vector-averaging current meter (VACM) in $10 \mathrm{~m}$ served as a reference mooring. The second mooring had its float in $5 \mathrm{~m}$ depth during the first 17 days of the experiment and in $2.7 \mathrm{~m}$ in the last five days in order to cause increased surface-wave induced mooring motions.

Two of the instruments intercompared were rotor instruments: The Aanderaa current meter (ACM) and the VACM; for both of which an extensive intercomparison literature under different environmental conditions exists. The third instrument was a pendulum current meter, the Niskin wing current meter (NWCM) and the fourth one an acoustic current meter developed by Gytre (GACM). The latter two instruments which both work with the burstsampling technique were studied because of potential advantages against rotor instruments under certain conditions. The GACM which was one of the first delivered, had several inconvenient shortcomings, especially too large a power consumption, causing it to stop during the first phase of the experiment. Also, the absolute direction could not be measured, only the current direction relative to the instrument housing, due to failure of one component of the fluxgate compass. The basic performance of the GACM, though, which was moored in $7.4 \mathrm{~m}$ depth on the wave-affected mooring was about equal to that of the VACM in $10 \mathrm{~m}$ depth on the less wave-affected reference mooring. The Aanderaa meter, in $8.4 \mathrm{~m}$ depth, on the same mooring as the GACM showed a vector variance an order of magnitude larger as the GACM during the phase when the top float of this mooring was close to the surface. The poorest performance was observed by the NWCM. It showed the largest vector variance, more than a factor of 20 larger than the Aanderaa on the same mooring in part of the first phase of around 10 December, when a strong wind period occurred. The calibration curve and the zero offset for the tilt provided by the manufacturer yielded negative speeds for $77 \%$ of the speeds. The offset was arbitrarily corrected to leave only $14 \%$ of the speeds negative. It should be emphasized that the design of the wing was for higher currents - as representative for an area where we wanted to do the experiment in the first place but could not go due to logistic reasons - which means that most of the speeds measured were in a rather insensitive part of the tilt calibration curve of the NWCM.

\section{Acknowledgement}

We thank C. Casagrande for providing us the NWCM for our current meter experiment. This work has been supported by Deutsche Forschungsgemeinschaft, Bonn-Bad Godesberg. It is contribution number 254 of the special research project SFB 95 at Kiel University.

\section{References}

(a) Manufacturex's instruction manuals Aanderaa: Operating manual for recording current meter. Serial no. 42-66, [undated], I.R. Aanderaa, Nesttun, Norway.

Gytre acoustic current meter: A profiling oceanographic data collecting instrument. Chr. Michelsen Institute Ref. 75100-1, Bergen, Norway (1976).
Niskin wing current meter: Current meter model 6011 instruction manual. General Oceanics Ine., Miami, Florida, U.S.A. (1976).

VACM: Vector averaging current meter. AMF Electrical Products Development Division of AMF Inc. Alexandria, Virginia, U.S.A. (1973). 
(b) Other references

Aanderaa, J., 1964: A recording and telemetering instrument. Techn. Rep. NATO Subcommitt. Oceanogr. Res. No. 16, 46 S., 20 Abb.

Beardsley, R. C., W. Boicourt, L. C. Huff, et al., 1977: CMICE 76: A current meter intercomparison experiment conducted off Long Island in February-March 1976. Techn. Rep. Woods Hole Oceanogr. Instn 77-62, $123 \mathrm{pp}$. [unpublished manuseript].

Bonde, L. W., 1978: Comparative testing of Niskin and vector averaging current meters. Techn. Rep. U. S. Office of Naval Res. No. TR 4618-0001, 17 pp.

Collar, P. G. and T.J. P. Gwilliam, 1977: Some laboratory measurements on an acoustic current meter developed at Christian Michelsen Institute, Norway. Rep. Inst. Oceanogr. Sci. 47, $15 \mathrm{pp}$.

Dahl, D., 1969 : The capability of the Aanderaa recording and telemetering instrument. In: Progress in Oceanography 5 (M. Sears, ed.), Pergamon Press, pp. 103-106.

Geyer, D., 1964: Figensehwingungen und Erneuerung des Wassers in der Eckernförder Bucht unter besonderer Berücksichtigung der Sturmlage vom 5.-6. Dezember 1961. Ph. D. Thesis, Univ. Kiel, $58 \mathrm{pp}$.

Gould, W.J. and E. Sambucco, 1975: The effect of mooring type on measured values of ocean currents. Deep-Sea Res. 29, 55-62.

Gytre, T., 1976: The use of a high sensitivity ultrasonic current meter in an oceanographic data aquisation system. Radio Electron. Eng. 46, 617-623.
Halpern, D., R. D. Pillsbury and R. L. Smith, 1974: An intercomparison of three current meters operated in shallow water. Deep-Sea Res. 21, 489-497.

Halpern, D. and R.D. Pillsbury, 1976: Near-surface moored current meter measurements. Mar. Technol. Soc. J. 10, 32-38.

McCullogh, J.R., 1975: Vector averaging current meter speed calibration and recording technique. Techn. Rep. Woods Hole Oceanogr. Instn 75-44, 35 pp. [unpublished manuscript].

Quadfasel, D. and F. Schott, 1979: Comparison of different methods of current measurements. Dt. hydrogr. Z. 32, 27-38.

Rumohr, H., 1979: Hydrographische Dauerregistrierungen bei Boknis Eck $(20 \mathrm{mI})$, westliche Ostsee von 1975-1978. Rep. Sonderforschungsbereich 95, Kiel. 59.pp.

Saunders, P.M., 1976: Near-surface current measurements. Deep-Sea Res. 28, 249-258.

Unesco, 1969: An intercomparison of some current meters. I. SCOR Working Group 21. Unesco Techn. Pap. Mar. Sci. 11, 70 pp.

Unesco, 1974: An intercomparison of some current meters. II. SCOR Working Group 21. Unesco Techn. Pap. Mar. Sci. 17, 61 pp.

Unesco, 1975: An intercomparison of some current meters. III. SCOR Working Group 21. Unesco Techn. Pap. Mar. Sei. 23, 42 pp.

Walden, R. G., C. W. Collins, jr., P. R. Clay, et al., 1977: Validation testing of the DOCMS intermediate mooring. Techn. Rep. Woods Hole Oceanogr. Instn 77-53, 95 pp. [unpublished manuscript].

Eingegangen im August 1979

Anschrift der Verfasser:

Dr. Hermann Kuhn, Detlef Quadfasel, Dr. Walter Zenk, Institut für Meereskunde an der Universität Kiel, Düsternbrooker Weg 20, 2300 Kiel 1

Prof. Dr. Friedrich Schott, Rosenstiel School of Marine and Atmospheric Sciences, University of Miami, 4600 Rickenbacker Causeway, Miami, Florida 33149, U. S. A. 